ORIGINAL ARTICLE

\title{
FAT, E-cadherin, $\beta$ catenin, HER 2/neu, Ki67 immunoexpression, and histological grade in intrahepatic cholangiocarcinoma
}

\author{
J Settakorn, N Kaewpila, G F Burns, A S-Y Leong
}

J Clin Pathol 2005;58:1249-1254. doi: 10.1136/jcp.2005.026575

See end of article for authors' affiliations

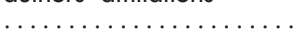

Correspondence to: Professor A S-Y Leong, Hunter Area Pathology Service, Locked Bag 1, HRMC, Newcastle, Australia 2310; aleong@ mail.newcastle.edu.au

Accepted for publication 19 May 2005
Aim: To identify surrogate prognostic markers in intrahepatic cholangiocarcinoma (IHCC).

Methods: Thirty one cases of IHCC were graded and immunostained for FAT, Ki67, E-cadherin, $\beta$ catenin, and HER 2/neu.

Results: Twenty two cases were high grade and 27 had high Ki67 counts. Strong membranous staining of HER 2/neu was found in 10 tumours and reduced membranous E-cadherin and $\beta$ catenin in 19 and 18 tumours, respectively. Nuclear localisation of $\beta$ catenin was identified in five tumours and 22 showed weak cytoplasmic staining of FAT. Strong HER 2/neu and weak FAT immunoexpression were significantly correlated with high histological grade $(p=0.01)$ and high Ki67 index $(p=0.03)$. Upregulation of HER $2 /$ neu was also significantly associated with nuclear localisation of $\beta$ catenin $(p=0.01)$. Reduced membranous $\beta$ catenin was significantly related to reduced membranous E-cadherin ( $p=0.03)$, weak staining for FAT $(p=0.01)$, and nuclear translocation of $\beta$ catenin $(p=0.04)$.

Conclusions: Reduced immunoexpression of E-cadherin and FAT at their normal membranous location may be potential prognostic markers, and the overexpression of HER $2 /$ neu and $\beta$ catenin nuclear translocation may have a role in cholangiocarcinogenesis.
O $\mathrm{n}$ average, $15 \%$ of liver cancers worldwide are (IHCCs), although this figure varies from one country to another. ${ }^{1}$ The age standardised incidence of IHCC is 78.8/10 males in northern Thailand, the highest in the world. ${ }^{2}$ Early detection of IHCC is difficult, and survival depends largely on the feasibility of complete surgical resection; the median survival in two large series was $5.7^{3}$ and 6.5 months. ${ }^{4}$ Histological grade is related to tumour size, presentation, and metastatic rate. ${ }^{5}$ Other histological parameters of poor prognosis include scirrhous subtype, lymphatic permeation, perineural invasion, and high tumour proliferation. ${ }^{6}$

"Early detection of intrahepatic cholangiocarcinoma is difficult, and survival depends largely on the feasibility of complete surgical resection"

Very few studies have examined the prognostic value of other biological parameters. Here, we examine the immunoexpression of several adhesion proteins-including FAT, Ecadherin, and $\beta$ catenin —and correlate them with recognised prognostic parameters in IHCC, namely, HER 2/neu, Ki67, and histological grade.

\section{MATERIALS AND METHODS}

Thirty one cases of IHCC, comprising 13 excisions, six wedge biopsies, and 12 core biopsies, accessioned during 12 months in 2001-2002, were retrieved from the files of the pathology department, Chiang Mai University, Thailand. There were 14 women (aged 43-72 years; mean, 55.79; SD, 7.62) and 17 men (aged 40-67 years; mean, 53.59; SD, 8.15). All tumours were of primary intrahepatic bile duct origin and were graded histologically into three grades according to the World Health Organisation system. ${ }^{7}$ Grade 1 (well differentiated) tumours were renamed low grade, and histological grades 2 (moderately differentiated) and 3 (poorly differentiated) were combined into a high grade group. Representative sections from formalin fixed, paraffin wax embedded blocks were subjected to immunohistological staining with antibodies to FAT, Ki67, HER 2/neu, E-cadherin, and $\beta$ catenin at the Hunter Area Pathology Service, Newcastle, Australia. All antibodies were incubated overnight at $22^{\circ} \mathrm{C}$ and a standard streptavidin-biotin procedure was used with diaminobenzidine as the chromogen; dilutions and sources were as follows: anti-FAT (1/5000; Professor G Burns, Cancer Research, Newcastle, Australia), anti-Ki67 (1/50; Dako, Sydney, Australia), anti-E-cadherin (1/300; Zymed, San Francisco, California, USA), anti- $\beta$ catenin (1/300; Zymed), and anti-HER 2/neu (1/50; Dako). Antigen retrieval was carried out as follows: FAT, citric acid/EDTA ( $\mathrm{pH} 8.0)$ at $98^{\circ} \mathrm{C}$ for 15 minutes; Ki67, citrate buffer $\left(\mathrm{pH} \mathrm{8.0)}\right.$ ) at $98^{\circ} \mathrm{C}$ for 15 minutes; HER 2/neu, citrate buffer $(\mathrm{pH} 6.0)$ at $110^{\circ} \mathrm{C}$ for 15 minutes; E-cadherin, citrate buffer $(\mathrm{pH} 6.0)$ at $110^{\circ} \mathrm{C}$ for 15 minutes; and $\beta$ catenin, citrate buffer $(\mathrm{pH} 6.0)$ at $110^{\circ} \mathrm{C}$ for 15 minutes.

The immunohistological stains were evaluated independently and without knowledge of the findings of other markers. Areas with the highest counts were assessed in the resection specimens. In total, 500 tumour cells were counted and a percentage of positive cells was obtained. In small biopsies, when less than 500 cells were available, all tumour cells in the section were evaluated. The concordance ratios were between 74.20 and 87.10; discordant results were discussed and a consensus reached. The Ki67 index was arbitrarily scored as low when $<10 \%$ of the tumour cells showed nuclear staining and as high when $>10 \%$ were stained (fig 1). The membrane expression of HER 2/neu was scored as either weak (staining of $<10 \%$ of tumour cells) or strong (staining of $>10 \%$ of tumour cells) (fig 2). The membranous expression of E-cadherin (fig 3) and $\beta$ catenin (fig 4) was designated as "preserved" if more than $90 \%$ of the tumour cells showed intact staining and "reduced" if

Abbreviation: IHCC, intrahepatic cholangiocarcinoma 

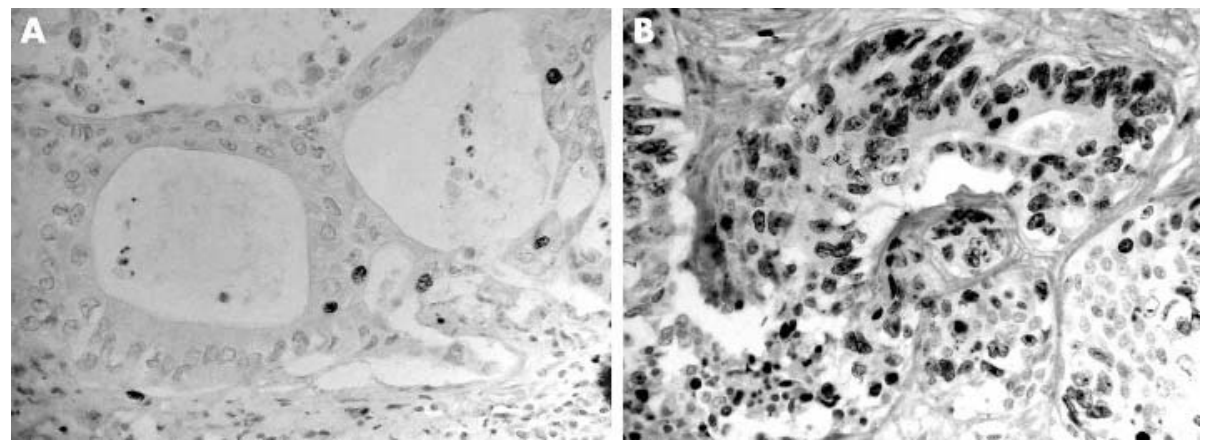

Figure 1 Ki67 immunostaining: (A) low Ki67 index in a low grade tumour; (B) high Ki67 index in a high grade tumour; original magnification, $\times 200$.
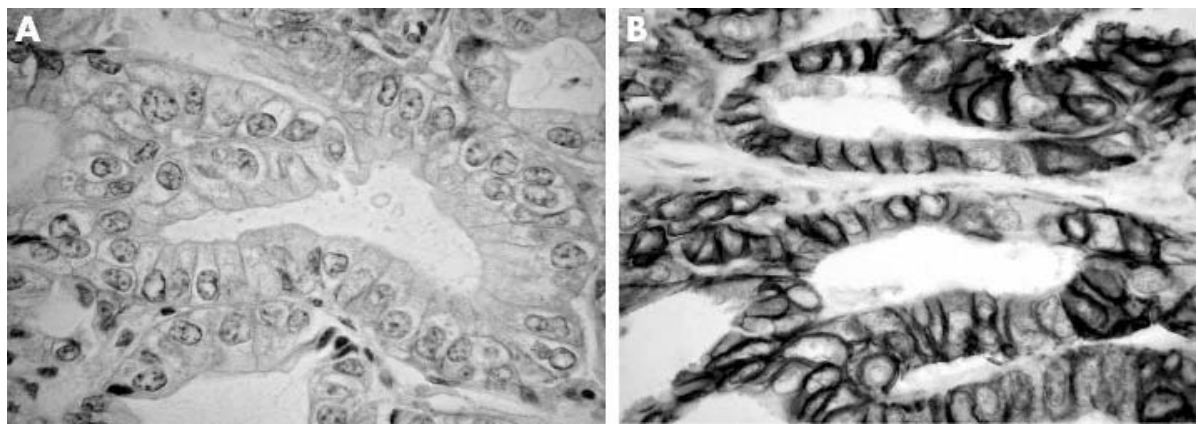

Figure 2 HER 2/neu immunostaining: (A) weak membranous staining in a low grade tumour; (B) strong membranous staining in a high grade tumour; original magnification, $\times 400$.
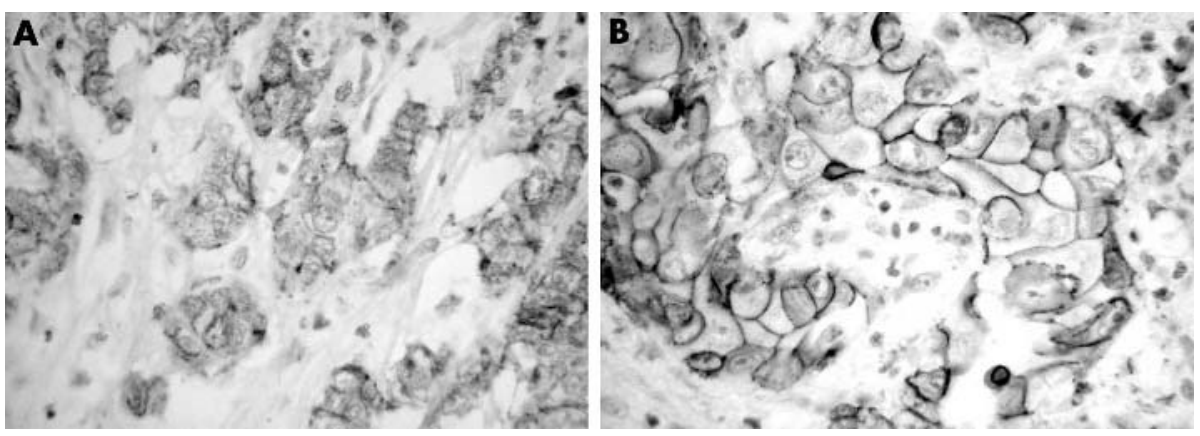

Figure 3 E-cadherin immunostaining (A) loss of membranous staining in a high grade tumour; original magnification, $\times 250$; (B) strong membranous staining in a low grade tumour; original magnification, $\times 400$.

otherwise. The cytoplasmic and nuclear localisation of these proteins was recorded as either present or absent. The cytoplasmic immunoexpression of FAT protein was scored as strong (staining intensity equal to or greater than that of normal bile duct epithelium or hepatocytes) and weak expression (negative or staining intensity less than that of normal bile duct epithelium or hepatocytes) (fig 5).

The tests of association between each of the markers, and between the markers and both Ki67 and tumour grade were performed using $\chi^{2}$ statistics. The $\chi^{2}$ test was also used to evaluate the relation between sex and each of these factors.
Kappa statistics were used to evaluate the degree of agreement between each pair of study factors. The KruskalWallis test was used to test for the differences between ages in each variable. Significance was set at 0.05. All analyses were implemented with the STATA statistic software, version 7.

\section{RESULTS}

Table 1 summarises the findings in the 31 IHCCs. Normal intrahepatic bile duct epithelium and hepatocytes were negative for Ki67 and HER 2/neu, and displayed strong
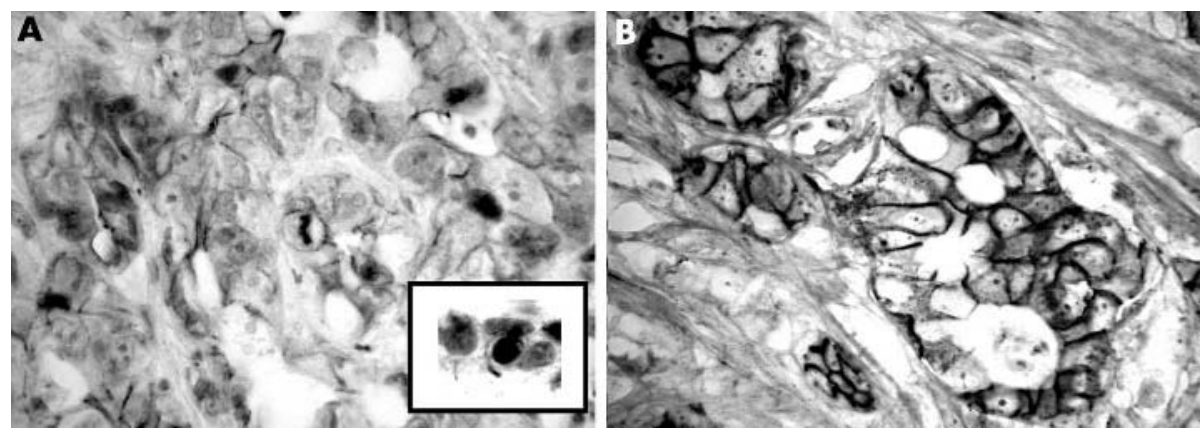

Figure $4 \quad \beta$ Catenin immunostaining: (A) loss of membranous staining in a high grade tumour; (B) well preserved membranous staining in a low grade tumour; the inset shows the nuclear localisation of $\beta$ catenin in the high grade tumour; original magnification, $\times 400$ 

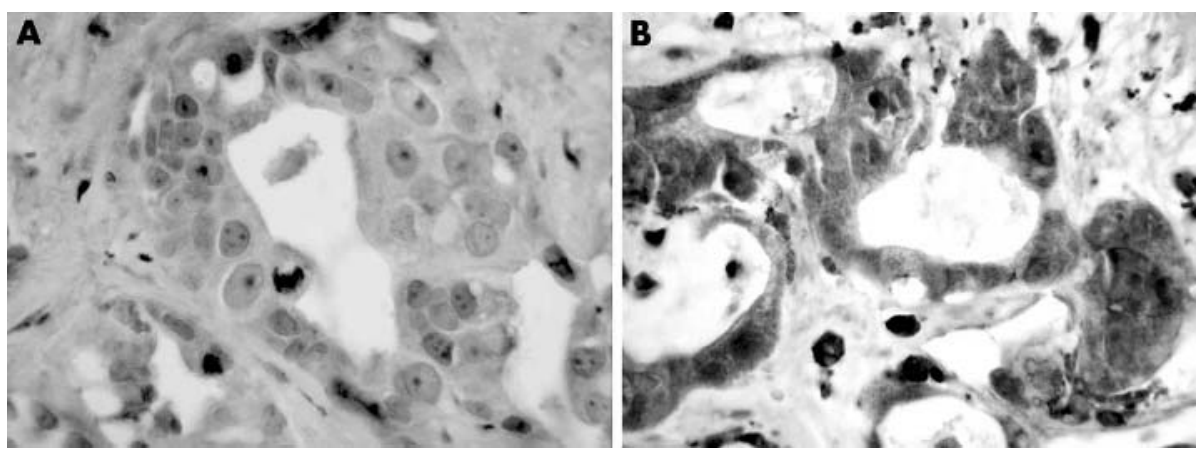

Figure 5 FAT immunostaining: (A) loss of cytoplasmic staining in a high grade tumour; (B) preserved granular cytoplasmic staining in a low grade tumour; original magnification, $\times 400$.

cytoplasmic staining for FAT and preserved membranous Ecadherin and $\beta$ catenin staining. Nine tumours were low grade. Twenty two IHCCs showed weak positivity for the FAT protein. Most tumours (27 of 31) showed high Ki67 immunoreactivity. Strong membranous staining of HER 2/ neu was found in 10 tumours. Membranous expression of Ecadherin and $\beta$ catenin was preserved in 12 of 31 and 13 of 31 tumours, respectively. All tumours showed fine granular cytoplasmic staining of weak to moderate intensity for Ecadherin and $\beta$ catenin. Focal nuclear localisation of $\beta$ catenin was identified in five tumours.

HER 2/neu was the only protein that showed a significant association with the histological grade $(p=0.01)$. Low expression of HER 2/neu was seen in all low grade (nine) and in 12 of 22 high grade IHCC cases (table 2). HER 2/neu showed a significant positive association with nuclear localisation of $\beta$ catenin $(p=0.01)$. Strong membranous staining of HER 2/neu was seen in six of 26 tumours negative for and four of five tumours positive for $\beta$ catenin nuclear staining.

Among the adhesion proteins studied, the membranous expression of $\beta$ catenin was negatively correlated with its nuclear localisation ( $p=0.04)$, positively correlated with the membranous expression of E-cadherin $(p=0.03)$, and positively correlated with strong staining of FAT protein $(p=0.01)$. Reduced membranous staining of $\beta$ catenin was seen in all tumours with positive $\beta$ catenin nuclear localisation (five), in 14 of 19 tumours with reduced E-cadherin expression, and in 16 of 22 tumours with weak FAT staining.

Finally, the FAT protein showed a significant inverse association with the Ki67 proliferative index $(p=0.03)$. High Ki67 activity was found in 21 of 22 tumours with weak FAT staining and in six of nine tumours with strong FAT staining.

Table 1 Histological grade and immunoexpression of FAT, Ki67, HER 2/neu, E-cadherin, and $\beta$ catenin in 31 cases of intrahepatic cholangiocarcinoma

\begin{tabular}{|c|c|c|c|c|c|c|c|c|c|}
\hline No & Sex & Age (years) & Grade* & Ki67† & HER 2/neu‡ & M-E-cad§ & $M-\beta$ cat- & $N-\beta$ cat $^{\star *}$ & FAT†t \\
\hline 1 & $\mathrm{~F}$ & 52 & 2 & $\mathrm{H}$ & W & $\mathrm{R}$ & $\mathrm{R}$ & $\mathrm{N}$ & W \\
\hline 2 & $M$ & 50 & 2 & $\mathrm{H}$ & $S$ & $\mathrm{R}$ & $\mathrm{R}$ & $P$ & W \\
\hline 3 & $M$ & 67 & 2 & $\mathrm{H}$ & $\mathrm{S}$ & $P$ & $\mathrm{R}$ & $P$ & W \\
\hline 4 & $\mathrm{~F}$ & 55 & 2 & $\mathrm{H}$ & $\mathrm{S}$ & $P$ & $P$ & $\mathrm{~N}$ & W \\
\hline 5 & $M$ & 44 & 1 & $\mathrm{H}$ & W & $\mathrm{R}$ & $\mathrm{R}$ & $\mathrm{N}$ & $S$ \\
\hline 6 & $M$ & 64 & 2 & $\mathrm{H}$ & $S$ & $\mathrm{R}$ & $\mathrm{R}$ & $P$ & W \\
\hline 7 & $\mathrm{~F}$ & 64 & 2 & $\mathrm{H}$ & W & $P$ & $P$ & $\mathrm{~N}$ & W \\
\hline 8 & $\mathrm{~F}$ & 52 & 3 & $\mathrm{~L}$ & W & $\mathrm{R}$ & $R$ & $\mathrm{~N}$ & $\mathrm{~S}$ \\
\hline 9 & $\mathrm{~F}$ & 50 & 3 & $\mathrm{H}$ & W & $\mathrm{P}$ & $\mathrm{R}$ & P & W \\
\hline 10 & $\mathrm{~F}$ & 52 & 2 & $\mathrm{H}$ & W & $\mathrm{R}$ & $\mathrm{R}$ & $\mathrm{N}$ & W \\
\hline 11 & $\mathrm{~F}$ & 56 & 3 & $\mathrm{H}$ & W & $\mathrm{R}$ & $\mathrm{R}$ & $N$ & W \\
\hline 12 & $M$ & 53 & 1 & $\mathrm{H}$ & W & $\mathrm{R}$ & $\mathrm{R}$ & $\mathrm{N}$ & W \\
\hline 13 & $M$ & 63 & 1 & $\mathrm{H}$ & W & $\mathrm{R}$ & $\mathrm{R}$ & $\mathrm{N}$ & W \\
\hline 14 & $M$ & 42 & 1 & $\mathrm{H}$ & W & $\mathrm{R}$ & $\mathrm{R}$ & $\mathrm{N}$ & W \\
\hline 15 & $M$ & 55 & 3 & $\mathrm{H}$ & W & $\mathrm{R}$ & $\mathrm{R}$ & $\mathrm{N}$ & W \\
\hline 16 & $M$ & 47 & 2 & $\mathrm{H}$ & $\mathrm{S}$ & $P$ & $P$ & $N$ & W \\
\hline 17 & $\mathrm{~F}$ & 64 & 1 & $\mathrm{H}$ & W & $\mathrm{R}$ & $P$ & $\mathrm{~N}$ & $\mathrm{~S}$ \\
\hline 18 & $\mathrm{~F}$ & 52 & 3 & $\mathrm{~L}$ & W & $P$ & $P$ & $\mathrm{~N}$ & W \\
\hline 19 & $\mathrm{~F}$ & 55 & 1 & $\mathrm{H}$ & W & $\mathrm{R}$ & $\mathrm{R}$ & $\mathrm{N}$ & W \\
\hline 20 & $\mathrm{~F}$ & 64 & 1 & $\mathrm{H}$ & W & P & $\mathrm{R}$ & $\mathrm{N}$ & W \\
\hline 21 & $M$ & 47 & 2 & $\mathrm{H}$ & $\mathrm{S}$ & $\mathrm{R}$ & $\mathrm{R}$ & $\mathrm{N}$ & W \\
\hline 22 & $M$ & 47 & 2 & $\mathrm{~L}$ & W & $\mathrm{R}$ & $\mathrm{P}$ & $\mathrm{N}$ & $\mathrm{S}$ \\
\hline 23 & $M$ & 57 & 2 & $\mathrm{H}$ & $S$ & $\mathrm{R}$ & $\mathrm{R}$ & $\mathrm{N}$ & W \\
\hline 24 & $\mathrm{~F}$ & 50 & 2 & $\mathrm{H}$ & $S$ & P & $\mathrm{R}$ & P & W \\
\hline 25 & $M$ & 57 & 2 & $\mathrm{H}$ & W & $P$ & $\mathrm{P}$ & $N$ & W \\
\hline 26 & $M$ & 40 & 1 & $\mathrm{~L}$ & W & $\mathrm{R}$ & $P$ & $\mathrm{~N}$ & $S$ \\
\hline 27 & $\mathrm{~F}$ & 72 & 1 & $\mathrm{H}$ & W & $P$ & $P$ & $\mathrm{~N}$ & $S$ \\
\hline 28 & $\mathrm{~F}$ & 43 & 2 & $\mathrm{H}$ & W & $P$ & $P$ & $N$ & $\mathrm{~S}$ \\
\hline 29 & $M$ & 60 & 2 & $\mathrm{H}$ & W & $\mathrm{R}$ & $P$ & $\mathrm{~N}$ & W \\
\hline 30 & $M$ & 57 & 2 & $\mathrm{H}$ & $\mathrm{S}$ & $P$ & $P$ & $\mathrm{~N}$ & $\mathrm{~S}$ \\
\hline \multirow[t]{3}{*}{31} & M & 61 & 2 & $\mathrm{H}$ & $\mathrm{S}$ & $\mathrm{R}$ & P & $\mathrm{N}$ & $\mathrm{S}$ \\
\hline & $M=17$ & & $1=9$ & $\mathrm{~L}=4$ & $W=21$ & $R=19$ & $R=18$ & $N=26$ & $W=22$ \\
\hline & $\mathrm{F}=14$ & & $\begin{array}{l}2=17 \\
3=5\end{array}$ & $\mathrm{H}=27$ & $S=10$ & $P=12$ & $P=13$ & $P=5$ & $\mathrm{~S}=9$ \\
\hline
\end{tabular}

*Tumour grade: $\mathrm{L}$, low; $\mathrm{H}$, high $+\mathrm{Ki} 67$ : $\mathrm{H}>10 \%$ positive; $\mathrm{L},<10 \%$ positive; tHER $2 /$ neu membranous staining: $\mathrm{S}$, strong $(>10 \%$ stainingl: W, weak $(<10 \%$ staining); §membranous E-cadherin: $P$, preserved; $R$, reduced; 9 membranous $\beta$ catenin staining: $P$, preserved; $R$, reduced; ${ }^{* *}$ nuclear $\beta$ catenin translocation; $P$, positive; N, negative; ††FAT: S, strong cytoplasmic staining; $W$, weak cytoplasmic staining. 
Table 2 Correlation between HER 2/neu, $\beta$ catenin, and Ki67 and the other studied parameters

\begin{tabular}{|c|c|c|c|c|}
\hline & & \multicolumn{2}{|l|}{ HER 2/neu } & \multirow[b]{2}{*}{ p Value } \\
\hline & & Strong $(\%)$ & Weak (\%) & \\
\hline Histological grade & $\begin{array}{l}\text { High } \\
\text { Low }\end{array}$ & $\begin{array}{l}10(45.45) \\
0(0)\end{array}$ & $\begin{array}{l}12(54.55) \\
9(100.00)\end{array}$ & 0.01 \\
\hline \multirow[t]{3}{*}{ Nuclear $\beta$ catenin } & $\begin{array}{l}\text { Present } \\
\text { Absent }\end{array}$ & $\begin{array}{l}4(80) \\
6(23.08)\end{array}$ & $\begin{array}{l}1(20) \\
20(76.92)\end{array}$ & 0.01 \\
\hline & & \multicolumn{2}{|c|}{ Membrane $\beta$ catenin } & \\
\hline & & Reduced (\%) & Preserved (\%) & \\
\hline Nuclear $\beta$ catenin & $\begin{array}{l}\text { Present } \\
\text { Absent }\end{array}$ & $\begin{array}{l}5(100) \\
13(50)\end{array}$ & $\begin{array}{l}0(0) \\
13(50)\end{array}$ & 0.04 \\
\hline Membrane E-cadherin & $\begin{array}{l}\text { Reduced } \\
\text { Preserved }\end{array}$ & $\begin{array}{l}14(73.68) \\
4(33.33)\end{array}$ & $\begin{array}{l}5(26.32) \\
8(66.67)\end{array}$ & 0.03 \\
\hline \multirow[t]{3}{*}{ FAT } & $\begin{array}{l}\text { Weak } \\
\text { Strong }\end{array}$ & $\begin{array}{l}16(72.73) \\
2(22.22)\end{array}$ & $\begin{array}{l}6 \text { (27.27) } \\
7 \text { (77.78) }\end{array}$ & 0.01 \\
\hline & & \multicolumn{2}{|l|}{ Ki67 } & \\
\hline & & High (\%) & Low (\%) & \\
\hline FAT & $\begin{array}{l}\text { Weak } \\
\text { Strong }\end{array}$ & $\begin{array}{l}21(95.45) \\
6(66.67)\end{array}$ & $\begin{array}{l}1(4.55) \\
3(33.33)\end{array}$ & 0.03 \\
\hline
\end{tabular}

Table 3 shows the $\kappa$ statistics results. The findings are consistent with those from the test of association-that is, strong membranous staining of HER 2/neu was significantly correlated with high histological grade and nuclear localisation of $\beta$ catenin; reduced membranous staining of $\beta$ catenin was significantly correlated with reduced membranous expression of E-cadherin, nuclear localisation of $\beta$ catenin, and reduced staining of FAT; and a high Ki67 index was significantly correlated with reduced staining of FAT. The $\kappa$ values ranged from 0.24 to 0.45 .

There was no association between age or sex and all variables examined $(\mathrm{p}>0.05)$.

\section{DISCUSSION}

We found a strong correlation between HER 2/neu and FAT expression and other adhesion proteins studied, in addition to tumour grade and Ki67 immunoreactivity. Weak membranous staining of HER 2/neu was found in all cases of low grade IHCC. The overexpression of this protein showed a significant positive association with the nuclear localisation of $\beta$ catenin. Previous studies have shown HER 2/neu overexpression in IHCC, with percentages varying from $26 \%$ to $82 \% .^{8-13}$ A significant correlation between high HER 2/neu expression and lymph node metastasis has been noted. ${ }^{12}$ In contrast to our results, Endo et al found a significant association between strong immunostaining of HER 2/neu and well differentiated IHCC. ${ }^{14}$ Although both studies used the same semiquantitative method of assessment, they used a monoclonal antibody whereas ours was polyclonal.
This is the first reported study of FAT protein in IHCC. The FAT gene on chromosome bands $4 \mathrm{q} 34-35$ encodes a protein that closely resembles the drosophila tumour suppressor FAT. ${ }^{15}$ This transmembrane protein, a new member of the cadherin superfamily, contains a large extracellular domain of 34 cadherin repeats (a classic cadherin molecule consists of only five extracellular cadherin repeats), five epidermal growth factor repeats, and two laminin-A G repeats. ${ }^{16}$ The intracytoplasmic domain contains two protein blocks of 137 and 84 amino acids that are homologous to the cadherincatenin binding region. ${ }^{17}$ It is likely that $\beta$ catenin binds to the intracytoplasmic domain of FAT and that the interaction between FAT and $\beta$ catenin is involved in Wnt signalling and the degradation of $\beta$ catenin. ${ }^{18}$

FAT expression showed a significant inverse association with the Ki67 index $(\mathrm{p}=0.03)$. High Ki67 activity was found in 21 of 22 tumours with weak membranous FAT staining and in six of nine tumours with strong membranous FAT staining. Thus, FAT may also play a role in the progression and carcinogenesis of IHCC, with loss of membrane localisation correlating with more aggressive tumours. Alternatively, the immunoreactivity pattern of FAT mirrors alterations in E-cadherin and $\beta$ catenin and reflects the loss of these proteins at their membranous location.

The $\beta$ catenin protein forms an intracytoplasmic complex with $\alpha$ catenin, actin, and the intracytoplasmic domain of E-cadherin to maintain normal cellular structure and cellcell adhesion. ${ }^{19}$ There is evidence that $\beta$ catenin binds

Table 3 Kappa statistic (p value) of Ki67, HER 2/neu, E-cadherin, $\beta$ catenin, FAT, and histological grade in 31 intrahepatic cholangiocarcinomas

\begin{tabular}{|c|c|c|c|c|c|c|}
\hline & Ki67 & HER 2/neu & M-E-cadherin & $M-\beta$ catenin & $N-\beta$ catenin & FAT \\
\hline $\begin{array}{l}\text { H grade } \\
\text { Ki67 } \\
\text { HER 2/neu } \\
M-E-\text { cadherin } \\
M-\beta \text { catenin } \\
N-\beta \text { catenin }\end{array}$ & $-0.03(0.58)$ & $\begin{array}{l}0.33(<0.01) \\
0.1318(0.0696)\end{array}$ & $\begin{array}{l}-0.21(0.89) \\
-0.09(0.73) \\
-0.13(0.81)\end{array}$ & $\begin{array}{l}-0.11(0.73) \\
0.19(0.08) \\
0.02(0.44) \\
0.40(0.01)\end{array}$ & $\begin{array}{l}0.15(0.06) \\
0.05(0.17) \\
0.41(<0.01) \\
-0.12(0.86) \\
0.24(0.02)\end{array}$ & $\begin{array}{l}0.22(0.11) \\
0.34(0.02) \\
0.10(0.65) \\
-0.07(0.65) \\
0.45(<0.01) \\
0.15(0.06)\end{array}$ \\
\hline
\end{tabular}

Results in bold are significant.

$\mathrm{H}$ grade, high histological grade; Ki67, high Ki67 index (>10\%); HER 2/neu, strong membranous staining of HER 2/neu; M-E-cadherin, reduced membranous staining of E-cadherin; $M-\beta$ catenin, reduced membranous staining of $\beta$ catenin; $N$ - $\beta$ catenin, positive nuclear staining of $\beta$ catenin; FAT, reduced immunoexpression of FAT. 
competitively with E-cadherin and HER 2/neu. ${ }^{20}$ A positive correlation between $\beta$ catenin and HER 2/neu has been shown in human cholangiocarcinoma. ${ }^{21}$ Moreover, excess $\beta$ catenin can enter the nucleus to activate the transcription of growth promoting genes. Altered expression of $\beta$ catenin, such as nuclear or cytoplasmic immunolocalisation and loss of membranous expression, and activating mutations in exon 3 of the $\beta$ catenin gene, have been found in cholangiocarcinoma and other tumours. ${ }^{22} 23$

"Our findings support the concept that, in normal cells and low grade tumours, HER 2/neu binds to the intracytoplasmic domain of E-cadherin and to $\mathrm{FAT}^{\prime \prime}$

Eighteen and five tumours showed reduced membranous expression of $\beta$ catenin or nuclear localisation, respectively. All five tumours with nuclear $\beta$ catenin expression showed reduced membranous $\beta$ catenin staining. These results correspond to those of Sugimachi et al, ${ }^{23}$ who found reduced membranous expression of $\beta$ catenin in 58 of 71 IHCCs and nuclear localisation in 11 tumours, suggesting that such abnormalities play a role in cholangiocarcinogenesis. The HER 2/neu protein has been shown by western blotting analysis to associate directly with $\beta$ catenin through its cytoplasmic domain core region, which has extensive homology with the epidermal growth factor receptor. ${ }^{24}$ It is thought that in human cancers HER 2/neu induced signalling is directly linked to the cadherin mediated cell adhesion system through $\beta$ catenin. In the only other study of Ecadherin, $\beta$ catenin, HER 2/neu, and Ki-67 in cholangiocarcinoma, Ashida and colleagues ${ }^{21}$ found downregulation of Ecadherin in eight of 18 low grade and 17 of 29 high grade tumours in 47 Japanese patients. The expression of Ecadherin and $\beta$ catenin correlated significantly with histological grade-the expression of these adhesion molecules tended to be weak in high grade IHCC. However, in contrast to our results, they found that $\beta$ catenin downregulation was significantly correlated with weak HER 2/neu staining.. As with our previous observations in breast cancer, ${ }^{22}$ the loss of membranous expression of E-cadherin may be the stimulus for a cascade of events that result in loss of membrane binding of $\beta$ catenin and other proteins. The loss of membrane expression of E-cadherin and $\beta$ catenin that occurs in high grade tumours results in increased free cytoplasmic $\beta$ catenin, which, in turn, translocates to the nucleus and increases cellular proliferation. ${ }^{25} 26$

Kappa statistics confirmed the presence of associations between the studied variables. The $\kappa$ statistic values of the pairs with significant agreement were 0.24 to 0.45 and were within the expected range. They were relatively high in view of the complexity of the variables in carcinogenesis.

\section{Take home messages}

- The overexpression of HER $2 /$ neu and nuclear translocation of the cell adhesion molecule $\beta$ catenin may play a role in cholangiocarcinogenesis

- Reduced immunoexpression of cell adhesion molecules E-cadherin and FAT at their normal membranous location may be potential markers of poor prognosis in intrahepatic cholangiocarcinoma

- Further studies with prospective patient follow up are required to validate the prognostic value of these immunohistological markers
Our findings suggest that most IHCCs tend to be high grade tumours with high Ki67 counts; HER 2/neu and FAT protein may be useful prognostic markers in IHCC. The loss of membranous localisation of the cadherin superfamily molecules-E-cadherin, $\beta$ catenin, and FAT-overexpression of HER 2/neu, and nuclear translocation of $\beta$ catenin are indicators of IHCC progression and correlate with other confirmed markers of poor prognosis; namely, Ki67 index and histological grade. Confirmation of the prognostic value of these immunohistological markers awaits prospective patient follow up.

\section{ACKNOWLEDGEMENTS}

Thanks to Drs J Attia for assistance in statistical analyses, and C YaIn, K Wasanavijit, B Chaiwun, and S Rangdeang for the cases in this study.

\section{Authors' affiliations}

J Settakorn, Hunter Area Pathology Service, Locked Bag 1, HRMC, Newcastle, Australia 2310

N Kaewpila, Hunter Area Pathology Service, Newcastle, Australia G F Burns, Cancer Research Unit, University of Newcastle, Australia A S-Y Leong, Hunter Area Pathology Service

\section{REFERENCES}

1 Okuda K, Nakanuma Y, Miyazaki M. Cholangiocarcinoma: recent progress. Part 1: epidemiology and etiology. J Gastroenterol Hepatol 2002; 17:1049-55

2 Srivatanakul P, Parkin DM, Jiang YZ, et al. The role of infection by Opisthorchis viverrini, hepatitis B virus, and aflatoxin exposure in the etiology of liver cancer in Thailand. A correlation study. Cancer 1991;68:241 1-17.

3 Ishak KG, Goodman ZD, Stocker JT. Tumors of the liver and intrahepatic bile ducts. In: Rosai J, Sobin LH, eds. Atlas of tumor pathology, 3rd series. Washington, DC: AFIP, 2001:245-70.

4 Okuda K, Kubo Y, Okazaki N, et al. Clinical aspects of intrahepatic bile duct carcinoma including hilar carcinoma: a study of 57 autopsy-proven cases. Cancer 1977;39:232-46.

5 Anthony PP. Primary carcinoma of the liver: a study of 282 cases in Ugandan Africans. J Pathol 1973;110:37-48.

6 Kajiyama K, Maeda T, Takenaka K, et al. The significance of stromal desmoplasia in intrahepatic cholangiocarcinoma: a special reference of "scirrhous-type" and "nonscirrhous-type" growth. Am J Surg Pathol 1999;23:892-902.

7 Nakanuma $Y$, Sripa B, Vatanasapt $\mathrm{V}$, et al. Intrahepatic cholangiocarcinoma. In: Hamilton SR, Aaltonen LA, eds. WHO classification of tumours. Pathology and genetics of fumours of the digestive system. Lyon: IARC Press, 2000:173-80.

8 Terada T, Ashida K, Endo K, et al. C-ERBB-2 protein is expressed in hepatolithiasis and cholangiocarcinoma. Histopathology 1998;33:325-31.

9 Suzuki H, Isaji S, Pairojkul C, et al. Comparative clinicopathological study of resected intrahepatic cholangiocarcinoma in northeast Thailand and Japan. $J$ Hepatobiliary Pancreat Surg 2000;7:206-11.

10 Chow NH, Huang SM, Chan SH, et al. Significance of c-erbB-2 expression in normal and neoplastic epithelium of biliary tract. Anticancer Res 1995; 15:1055-9.

11 Ito Y, Takeda T, Sasaki Y, et al. Expression and clinical significance of the erbB family in intrahepatic cholangiocellular carcinoma. Pathol Res Pract $2001 ; 197: 95-100$

12 Ukita $Y$, Kato M, Terada T. Gene amplification and mRNA and protein overexpression of c-erbB-2 (HER-2/neu) in human intrahepatic cholangiocarcinoma as detected by fluorescence in situ hybridization, in situ hybridization, and immunohistochemistry. J Hepatol 2002;36:780-5.

13 Aishima SI, Taguchi KI, Sugimachi K, et al. c-erbB-2 and c-Met expression relates to cholangiocarcinogenesis and progression of intrahepatic cholangiocarcinoma. Histopathology 2002;40:269-78.

14 Endo K, Yoon BI, Pairojkul C, et al. ERBB-2 overexpression and cyclooxygenase-2 up-regulation in human cholangiocarcinoma and risk conditions. Hepatology 2002;36:439-50

15 Dunne J, Hanby AM, Poulsom R, et al. Molecular cloning and tissue expression of FAT, the human homologue of the drosophila FAT gene that is located on chromosome $4 \mathrm{q} 34-\mathrm{q} 35$ and encodes a putative adhesion molecule. Genomics 1995;30:207-23.

16 Mahoney PA, Weber U, Onofrechuk P, et al. The FAT tumor suppressor gene in drosophila encodes a novel member of the cadherin gene superfamily. Cell 1991;67:853-68

17 Angst BD, Marcozzi C, Magee Al. The cadherin superfamily: diversity in form and function. J Cell Sci 2001;114:629-41

18 Adler PN, Charlton J, Liu J. Mutations in the cadherin superfamily member gene dachsous cause a tissue polarity phenotype by altering frizzled signaling. Development 1998;125:959-68.

19 Chang HJ, Jee CD, Kim WH. Mutation and altered expression of beta-catenin during gallbladder carcinogenesis. Am J Surg Pathol 2002;26:758-66. 
20 Ochiai A Akimoto S, Kanai Y, et al. c-erbB-2 gene product associates with catenins in human cancer cells. Biochem Biophys Res Commun 1994;205:73-8.

21 Ashida K, Terada T, Kitamura Y, et al. Expression of E-cadherin, alphacatenin, beta-catenin, and CD44 (standard and variant isoforms) in human cholangiocarcinoma: an immunohistochemical study. Hepatology 1998:27:974-82.

22 Sormunen R, Leong AS-Y, Vaaraniemi J, et al. E-cadherin and beta-catenin immunolocalization in infiltrating ductal carcinoma of the breast correlated with selected prognostic indices. J Pathol 1999;187:416-23.
23 Sugimachi K, Taguchi K, Aishima S, et al. Altered expression of beta-catenin without genetic mutation in intrahepatic cholangiocarcinoma. Mod Patho 2001;14:900-5.

24 Kanai Y, Ochiai A, Shibata T, et al. C-erbb-2 gene product directly associates with beta-catenin and plakoglobin. Biochem Biophys Res Commun 1995; 208: 1067-72.

25 Wood B, Leong AS-Y. Cell adhesion proteins-biology, detection and applications. Pathology 2003;35:101-6.

26 Fearon ER. Human cancer syndromes: clues to the origin and nature of cancer. Science 1997;278:1043-50.

\section{1 th European Forum on Quality Improvement in Health Care}

26-28 April 2006, Prague, Czech Republic

For further information please go to: www.quality.bmipg.com

Book early to benefit from a discounted delegate rate 